\title{
Abnormalities of glucose metabolism in spontaneously hypertensive rats
}

L.M.F.B. Gouveia',

I.C. Kettelhut ${ }^{2}$ and M.C. Foss ${ }^{1}$
Departamentos de ${ }^{1}$ Clínica Médica and ${ }^{2}$ Bioquímica, Faculdade de Medicina de Ribeirão Preto, U niversidade de São Paulo, Ribeirão Preto, SP, Brasil

\section{Correspondence}

M.C. Foss

Departamento de Clínica M édica

FMRP, USP

Av. Bandeirantes, 3900

14049-900 Ribeirão Preto, SP

Brasil

Research supported by FAEPA and CAPES. Publication supported by FAPESP.

Received January 7, 2000

Accepted July 25, 2000

\section{Abstract}

Abnormalities in glucose metabolism and insulin action are frequently detected in patients with essential hypertension. Spontaneously hypertensive rats (SHR) have been used as an experimental model to understand this pathological condition. The objective of the present study was to assess glucose metabolism and insulin action in SHR and Wistar rats under fed and fasting conditions. Peripheral glucose utilization was estimated by kinetic studies with $\left[6-{ }^{3} \mathrm{H}\right]$-glucose and gluconeogenetic activity was measured during continuous $\left[{ }^{14} \mathrm{C}\right]$-bicarbonate infusion. Plasma glucose levels were higher in the SHR group. Plasma insulin levels in the fed state were higher in the SHR group $(99.8 \pm 6.5 \mu \mathrm{M})$ than in the control group $(70.4 \pm 3.6 \mu \mathrm{M})$. Muscle glycogen content was reduced in SHR compared to control under the various experimental conditions. Peripheral glucose utilization was slightly lower in the SHR group in the fed state $(8.72 \pm 0.55$ vs $9.52 \pm 0.80 \mathrm{mg} \mathrm{kg}^{-1} \mathrm{~min}^{-1}$ in controls). Serum free fatty acid levels, hepatic glycogen levels, hepatic phosphoenolpyruvate carboxykinase activity and gluconeogenetic activity were similar in the two groups. The presence of hyperglycemia and hyperinsulinemia and the slightly reduced peripheral glucose utilization suggest the presence of resistance to the action of insulin in peripheral tissues of SHR. Hepatic gluconeogenesis does not seem to contribute to the metabolic alterations detected in these animals.

\section{Introduction}

Abnormalities in glucose metabolism and in peripheral tissue sensitivity to the action of insulin have been reported for patients with arterial hypertension $(1,2)$. Epidemiological evidence has supported the hypothesis which proposes the existence of a syndrome in which hyperinsulinemia may precede the development of arterial hypertension and changes in glucose and lipid metabolism (3-5). Several animal models,
Key words

- Peripheral glucose utilization

- Gluconeogenesis

- Insulin resistance

- Spontaneously hypertensive rats among them the spontaneously hypertensive rat (SHR) strain, have been used as experimental models in order to clarify the relationship between insulin resistance and arterial hypertension (6). However, studies conducted in order to assess the deficiency of insulin action in peripheral tissues of SHR have presented conflicting results (7-9). On this basis, the objective of the present study was to assess various parameters of glucose metabolism and insulin action as well as the peripheral utilization of glucose in SHR and 
Wistar rats, as estimated by kinetic studies with $\left[6-{ }^{3} \mathrm{H}\right]$-glucose and by gluconeogenetic activity measured during continuous infusion of $\left[{ }^{14} \mathrm{C}\right]$-bicarbonate. We also measured the activity of hepatic phosphoenolpyruvate carboxykinase (PEPCK), a key enzyme in the control of gluconeogenetic pathways, and blood glucose, free fatty acid and insulin levels, as well as hepatic and muscle glycogen content in SHR and Wistar rats under different experimental conditions.

\section{Material and Methods}

Male Wistar rats and SHR (Taconic Farms, Inc., Germantown, NY, USA) aged 16 to 20 weeks and weighing 230 to $280 \mathrm{~g}$ were kept in individual cages with free access to food and water. Fed and fasted rats were used in all experiments. To ensure uniform food intake and to decrease variation in metabolic parameters, the animals were fasted for about $6 \mathrm{~h}$ (from 11:00 p.m. to 5:00 a.m.) during the previous night until $3 \mathrm{~h}$ before the beginning of the experiments (at 8:00 a.m.), when they were permitted free access to the diet. Fasting was started after the end of this morning meal and blood was collected after 8 and $24 \mathrm{~h}$ of food restriction. The animals had access to water during this period. The fed and fasted protocols were used in all experiments.

Mean arterial pressure was measured by tail plethysmography. Blood $(0.5 \mathrm{ml})$ was collected from the tip of the tail of awake animals to determine plasma glucose and insulin. In the experiments in which sacrifice was necessary, the animals were decapitated. Blood samples for the determination of serum free fatty acids were collected when the animals were decapitated. Blood samples were centrifuged at 2,000 rpm to remove red cells and plasma was stored no longer than one week at $-20^{\circ} \mathrm{C}$.

Glycemia was determined by the glucose oxidase method (10), free fatty acids were measured by the colorimetric method of
Novak (11), and plasma insulin was estimated by double-antibody immunoassay (12). Hepatic and muscle glycogen was determined by the method of Sjörgren et al. (13). After decapitation, the liver and muscle of the abdominal wall were removed and $500 \mathrm{mg}$ of these tissues were placed in a tube with $30 \% \mathrm{KOH}$.

PEPCK activity was determined in hepatic cytosol by the method based on the $\left[\mathrm{H}^{14} \mathrm{CO}_{3}\right]$-oxaloacetate exchange reaction (14). The liver was homogenized in ice-cold $0.25 \mathrm{M}$ sucrose with a Teflon pestle homogenizer. The homogenate was centrifuged for $10 \mathrm{~min}$ at $600 \mathrm{~g}$ and recentrifuged at 12,000 $g$ for $15 \mathrm{~min}$. The supernatant fluid obtained was decanted and centrifuged at $105,000 \mathrm{~g}$ for $1 \mathrm{~h}$. All steps were carried out at $0-3^{\circ} \mathrm{C}$.

In vivo gluconeogenetic activity was determined by continuous $\left[{ }^{14} \mathrm{C}\right]$-bicarbonate infusion. Anesthetized rats were submitted to cannulation of the jugular veins and the experiments were performed on the morning of the next day, with the animals awake and freely moving in their cages. $\mathrm{NaH}^{14} \mathrm{CO}_{3}$ dissolved in bicarbonate-free Krebs-Ringer solution, $\mathrm{pH}$ 7.8, was infused into one of the cannulas inserted into the jugular veins with a Harvard type infusion pump at a rate of 60 $\mu \mathrm{l}\left(0.3 \mu \mathrm{Ci}\left[{ }^{14} \mathrm{C}\right]\right.$-bicarbonate $) / \mathrm{min}$. Blood samples $(0.3 \mathrm{ml})$ were obtained from the contralateral catheter at $5,10,15,20,25,30$ and $40 \mathrm{~min}$ after the beginning of infusion. $\left[{ }^{14} \mathrm{C}\right]$-Glucose was isolated and its radioactivity measured according to a previously described method (15).

Peripheral glucose utilization was estimated by analysis of the exponential curve for the disappearance of the radioactivity of injected [6- $\left.{ }^{3} \mathrm{H}\right]$-glucose. The jugular vein and femoral artery were cannulated in animals anesthetized with Nembutal ( $40 \mathrm{mg} / \mathrm{kg}$ body weight). After injection of $0.25 \mathrm{ml}$ physiological saline containing $5 \mu \mathrm{Ci}$ of $\left[6-{ }^{3} \mathrm{H}\right]$-glucose, $0.3 \mathrm{ml}$ samples of arterial blood were collected at 15 , 20, 30, 40, 60, 80 and $100 \mathrm{~min}$. The measurement of sample radioactivity and the calcula- 
tion of glucose metabolism parameters were based on the method of Katz et al. (16).

Data were analyzed statistically by the Student $t$-test, with the level of significance set at $\mathrm{P}<0.05$.

\section{Results}

Mean arterial pressure was significantly higher in SHR than in Wistar rats $(194 \pm 3 v s$ $120 \pm 0 \mathrm{mmHg}$ ). In the fed state, mean body weight was $260.0 \pm 1.1 \mathrm{~g}$ for Wistar rats and $255.6 \pm 3.1 \mathrm{~g}$ for SHR. In the fasting state, body weight was similarly reduced in Wistar rats and SHR $(240.0 \pm 1.5$ and $231.6 \pm 2.7 \mathrm{~g}$, respectively).

Plasma glucose levels were significantly higher in SHR $(7.95 \pm 0.24 \mathrm{mM})$ than in the control group $(7.21 \pm 0.18 \mathrm{mM})(\mathrm{P}=0.0163)$. Food restriction caused a significant and similar fall in glycemia in both groups, with the hypertensive animals continuing to present higher levels after a 24-h fast (Table 1). Serum insulin was significantly higher in SHR both in the fed state $(99.8 \pm 6.5 v s 70.4 \pm 3.6 \mu \mathrm{M})(\mathrm{P}=$ $0.0003)$ and after an 8 -h fast ( $58.9 \pm 6.5 v s 35.9$ $\pm 5.0 \mu \mathrm{M})(\mathrm{P}=0.0073)$ compared to the control group (Table 1). Free fatty acid levels were low in the fed state and increased after the 24-h fast, with similar behavior in the two groups (Table 1).

Muscle glycogen concentrations in the fed state were significantly lower in the hypertensive group $(0.262 \pm 0.018 \mathrm{~g} / 100 \mathrm{~g}$ muscle) than in the control group (0.394 \pm $0.029 \mathrm{~g} / 100 \mathrm{~g}$ muscle $)(\mathrm{P}=0.0055)$. After the period of food restriction, there was a similar fall in both groups, so that in the fasting state SHR continued to have a lower content of muscle glycogen. Hepatic glycogen levels were similar for both groups in the fed state $(4.878 \pm 0.195 \mathrm{~g} / 100 \mathrm{~g}$ liver in SHR and $4.538 \pm 0.191 \mathrm{~g} / 100 \mathrm{~g}$ liver in Wistar rats) and were similarly and markedly reduced after the period of food restriction (Table 1).

PEPCK activity did not differ between groups in the fed state and was similarly and significantly increased in both groups after the 24-h fast (Table 1).

Gluconeogenetic activity was significantly increased in both groups during the fasting state compared to the fed state. These data again showed a similar behavior in the Wistar and SHR groups (Figure 1).

Table 1 - Plasma glucose, insulin and serum free fatty acid (FFA) levels, muscle and hepatic glycogen content and hepatic phosphoenolpyruvate carboxykinase (PEPCK) activity in SHR and in the control group (Wr) in the fed state and after an 8- and 24-h fast.

** PEPCK activity: $\mathrm{ppm} \times 10^{-3} \mathrm{mg}$ of protein-1 $\mathrm{min}^{-1}$ per $106 \mathrm{ppm}$ of added radioactivity. Data are reported as means $\pm \mathrm{SEM} . * \mathrm{P}<0.05$ compared to control (Student t-test).

\begin{tabular}{lllll}
\hline & & \multicolumn{1}{c}{ Fed } & Fasted $-8 \mathrm{~h}$ & Fasted $-24 \mathrm{~h}$ \\
\hline Glucose $(\mathrm{mM})$ & $\mathrm{Wr}(\mathrm{N}=24)$ & $7.21 \pm 0.18$ & $7.41 \pm 0.19$ & $4.20 \pm 0.14$ \\
& $\mathrm{SHR}(\mathrm{N}=24)$ & $7.95 \pm 0.24^{*}$ & $7.65 \pm 0.22$ & $4.71 \pm 0.16^{*}$ \\
Insulin $(\mu \mathrm{M})$ & $\mathrm{Wr}(\mathrm{N}=24)$ & $70.4 \pm 3.6$ & $35.9 \pm 5.0$ & $22.3 \pm 2.9$ \\
& $\mathrm{SHR}(\mathrm{N}=24)$ & $99.8 \pm 6.5^{*}$ & $58.9 \pm 6.5^{*}$ & $28.7 \pm 4.3$ \\
FFA $(\mu \mathrm{M})$ & $\mathrm{Wr}(\mathrm{N}=9)$ & $332.2 \pm 12.7$ & - & $1051.9 \pm 51.7$ \\
& $\mathrm{SHR}(\mathrm{N}=9)$ & $447.8 \pm 32.3$ & - & $1118.4 \pm 39.1$ \\
Muscle glycogen & $\mathrm{Wr}(\mathrm{N}=15)$ & $0.394 \pm 0.029$ & - & $0.187 \pm 0.007$ \\
(g/100 g muscle) & $\mathrm{SHR}(\mathrm{N}=15)$ & $0.262 \pm 0.018^{*}$ & - & $0.137 \pm 0.005^{*}$ \\
Hepatic glycogen & $\mathrm{Wr}(\mathrm{N}=15)$ & $4.538 \pm 0.191$ & - & $0.019 \pm 0.001$ \\
(g/100 g liver) & $\mathrm{SHR}(\mathrm{N}=15)$ & $4.878 \pm 0.195$ & - & $0.027 \pm 0.001$ \\
PEPCK activity*** & $\mathrm{Wr}(\mathrm{N}=9)$ & $3.42 \pm 0.25$ & - & $13.00 \pm 0.76$ \\
& $\mathrm{SHR}(\mathrm{N}=9)$ & $3.54 \pm 0.38$ & - & $12.96 \pm 0.71$
\end{tabular}

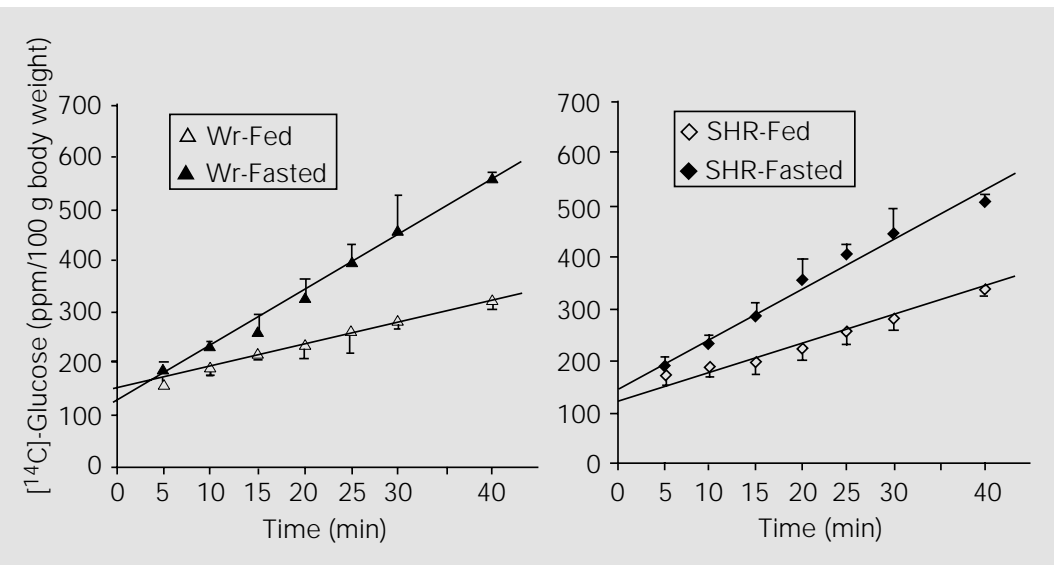

Figure $1-\left[{ }^{14} \mathrm{C}\right]$-Bicarbonate incorporation into circulating glucose during continuous infusion of $\left[{ }^{14} \mathrm{C}\right]$-bicarbonate in SHR and Wistar rats $(\mathrm{Wr})$ in the fed state and after a 24 -h fast. 
Plasma glucose concentration measured in each animal at the various times during the experiment showed a relatively low variation in amplitude, and fulfilled the conditions necessary for blood glucose equilibrium throughout the period of determination of peripheral glucose utilization. The correlation coefficients obtained for the time points studied were close to 1 , permitting us to conclude that the function between log radioactivity and time was strictly linear. Analysis of the angular coefficients of the lines, an estimate of the rate of relative glucose renewal, showed that the rate of $\left[6-{ }^{3} \mathrm{H}\right]-$ glucose disappearance from blood was higher in fed than in fasted animals, with no difference between groups. Glucose space and total glucose mass were similarly decreased in both groups when the animals were submitted to the 24-h fast. Peripheral glucose utilization was reduced in both groups after food restriction. SHR showed a tendency to renew their blood glucose in the fed state at a slightly lower rate than control animals (Table 2).

\section{Discussion}

Epidemiological evidence has demonstrated that the prevalence of hyperinsulinemia is higher in hypertensive patients than in the general population (3). Ferrannini et al. (1), using the euglycemic and hyperinsulinemic clamp technique, observed a lower utilization of glucose in peripheral tissues of hypertensive patients. As previously demonstrated by our group in individuals with arterial hypertension, this alteration is due to a lower glucose uptake by muscle tissue and to a lower utilization of this substrate in intracellular non-oxidative metabolism (2).

SHR is a genetic hypertension model without obesity, sharing common characteristics with primary hypertension in man. It was also observed that these animals are hyperglycemic (17) and the question has been raised whether these animals could be considered a model of hypertension and insulin resistance. In agreement with this possibility, our data showed higher glycemia values both in the fasted and in the fed state in SHR (Table 1). Swislocky et al. (18) also observed hyperglycemia in these animals after an oral glucose overload.

Serum insulin level was elevated in the fed state in the SHR group (Table 1). As also reported for the behavior of glycemia, other authors demonstrated normal or altered insulinemia in these animals (19).

Serum free fatty acid levels were similar for the two groups (Table 1), possibly reflecting a differential effect on the various actions of insulin, as previously observed in situations of insulin resistance and in human arterial hypertension itself (2).

Muscle glycogen content was lower in SHR both in the fed state and after glycogen mobilization in the fasting state (Table 1). This may have been due to a lower glucose uptake by muscle tissue with a consequent

Table 2 - Peripheral glucose utilization (PGU) in SHR and Wistar rats (Wr) in the fed state and after a 24-h fast.

Data are reported as means \pm SEM .

\begin{tabular}{|c|c|c|c|c|}
\hline & \multicolumn{2}{|c|}{ Fed } & \multicolumn{2}{|c|}{ 24-h fast } \\
\hline & $\operatorname{Wr}(\mathrm{N}=9)$ & SHR $(N=10)$ & $\operatorname{Wr}(\mathrm{N}=7)$ & SHR $(N=10)$ \\
\hline Correlation coefficient ( $r$ ) & $0.985 \pm 0.005$ & $0.980 \pm 0.044$ & $0.973 \pm 0.009$ & $0.991 \pm 0.002$ \\
\hline Angular coefficient (a) & $0.0151 \pm 0.0008$ & $0.0147 \pm 0.0008$ & $0.0123 \pm 0.0008$ & $0.0130 \pm 0.0009$ \\
\hline Glucose space (ml) & $165.2 \pm 11.5$ & $162.6 \pm 6.6$ & $191.9 \pm 10.1$ & $164.5 \pm 9.9$ \\
\hline Total glucose (mg) & $181.4 \pm 6.4$ & $169.1 \pm 6.7$ & $116.2 \pm 6.2$ & $128.7 \pm 8.4$ \\
\hline PGU (mg kg-1 $\left.\mathrm{min}^{-1}\right)$ & $9.52 \pm 0.80$ & $8.72 \pm 0.55$ & $5.32 \pm 0.43$ & $5.55 \pm 0.42$ \\
\hline
\end{tabular}


lower glucose storage in the form of glycogen. Adequate glycogen synthetase and phosphorylase activity was previously demonstrated in the muscle tissue of SHR (20), thus indicating alterations in some other steps of insulin action. The fact that we detected similar hepatic glycogen levels in both groups (Table 1) may reflect different metabolic responses to insulin depending on the tissue analyzed.

In the fed state the maintenance of glycemia is essentially determined by intestinal absorption of dietary carbohydrates. During the postabsorptive period, endogenous glucose production depends on glycogenolysis and, to a lesser extent, on gluconeogenesis. Studies conducted by Hulman et al. (8) using the technique of euglycemic and hyperinsulinemic clamp in combination with infusion of tritiated glucose demonstrated that SHR adequately suppressed the production of hepatic glucose. However, gluconeogenetic capacity was not evaluated in those animals. Our results show that SHR behave similarly to the control group in the fed state in terms of this parameter. With food restriction, gluconeogenetic activity increased due to a greater supply of substrates to the liver (Figure 1). Thus, hepatic glycogen content, PEPCK activity and gluconeogenetic activity were adequate in SHR, indicating that the occurrence of changes in insulin action at the hepatic tissue level was unlikely in these animals.

Changes in carbohydrate metabolism may be due to lower peripheral glucose utilization, to lower glucose utilization by the liver or to increased hepatic glucose production. Thus, to explain the behavior of glycemia observed in SHR it would be important to analyze peripheral glucose utilization. The only difference observed in peripheral glucose utilization, although nonsignificant, was that SHR in the fed state tended to renew blood glucose at a slightly lower rate than control animals. Reaven (5) demonstrated that glucose transport was reduced in SHR adipocytes. In vivo studies using the technique of glucose, insulin and somatostatin infusion revealed a lower response to the action of insulin (19), and studies using euglycemic and hyperinsulinemic clamp techniques demonstrated a reduced peripheral glucose utilization in $\operatorname{SHR}(7,8)$. In contrast, Buchanan et al. (9), using the clamp technique, observed peripheral glucose utilization similar to that of control animals. The lack of uniformity of the results obtained may result from the use of different techniques or of animals of different origin, weight or age.

One explanation for the correlation between insulin and blood pressure that has been proposed is that hypertension causes insulin resistance and hyperinsulinemia via increased peripheral vascular resistance and decreased delivery of glucose and insulin to peripheral tissues, especially skeletal muscle (21). However, even large reductions in skeletal muscle blood flow did not cause fasting hyperinsulinemia as occurs in insulin-resistant subjects (22) and essential hypertension is not accompanied by decreased blood flow to skeletal muscle (23).

Taken together, the present results show that the hyperglycemia detected in SHR seems to be the consequence of a defect at the muscle tissue level, since a lower muscle glycogen content was observed in these animals. The fact that the changes in peripheral glucose utilization were small in SHR may reflect a maintenance of adequate levels of glucose utilization due to greater insulinemia, thus reflecting a situation of antagonism against the metabolic action of this hormone.

\section{Acknowledgments}

The authors are grateful to Maria Antonieta Garófalo, Neusa Maria Resano, Sebastião Brandão Filho and Wilson Rodrigues for technical assistance. 


\section{References}

1. Ferrannini E, Buzzigoli G, Bonadonna R, Giorico MA, Oleggini M, Graziadei L, Pedrinelli R, Brandi L \& Bevilacqua $S$ (1987). Insulin resistance in essential hypertension. New England J ournal of Medicine, 317: 350-357.

2. Gouveia LMFB, Paccola GMFG, Torquato MTCG, Menezes FOM, Piccinato CE \& Foss MC (2000). Peripheral glucose metabolism in patients with essential hypertension. Hormone and Metabolic Research, 32: 35-39.

3. Modan M, Halkin H \& Almog S (1985). Hyperinsulinemia, a link between hypertension, obesity and glucose intolerance. J ournal of Clinical Investigation, 75: 809817.

4. Haffner SM, Ferrannini E, Hazuda HP \& Stern MP (1992). Clustering of cardiovascular risk factors in confirmed prehypertensive individuals. Hypertension, 20: 3845.

5. Reaven GM (1988). Role of insulin resistance in human disease. Diabetes, 37: 1595-1607.

6. Reaven GM, Chang $H$, Hoffman BB \& Azhar S (1989). Resistance to insulin-stimulated glucose uptake in adipocytes from spontaneously hypertensive rats. Diabetes, 38: 1155-1160.

7. Hulman S, Falkner B \& Chen YQ (1991). Insulin resistance in the spontaneously hypertensive rat. Metabolism, 40: 359361.

8. Hulman S, Falkner B \& Freyvogel N (1993). Insulin resistance in the conscious spontaneously hypertensive rat: eugly- cemic hyperinsulinemic clamp study. Metabolism, 42: 14-18.

9. Buchanan TA, Sipos GF, Madrilejo N, Liu C \& Campese VM (1992). Hypertension without peripheral insulin resistance in spontaneously hypertensive rats. American J ournal of Physiology, 25: E14-E19.

10. Hugget ASC \& Nixon DA (1988). Use of glucose oxidase, peroxidase and dianisidine in the determination of blood and urinary glucose. Lancet, 11: 368-370.

11. Novak M (1965). Colorimetric ultramicro method for the determination of free fatty acids. J ournal of Lipid Research, 6: 431433.

12. Soeldner J S \& Slone D (1965). Critical variables in the radioimmunoassay of serum insulin using the double antibody technique. Diabetes, 14: 771-779.

13. Sjörgren $B$, Nordenskjöld $T$, Holurgeem $H$ \& Möllerström J (1938). Beitrag zur Kenntnis der Leberrhythmik (Glykogen, Phosphor und Calcium) in der Kaninchenleber. Pflügers Archiv. European J ournal of Physiology, 240: 427-448.

14. Utter MF \& Kurahashi K (1955). Oxaloacetate synthesizing enzyme. Methods in Enzymology, 1: 758-763.

15. Baker N, Huebotter RJ \& Schotz MC (1965). Analysis of glucose ${ }^{14} \mathrm{C}$ in tissues using thin-layer chromatography. Analytical Biochemistry, 10: 227-235.

16. Katz J , Dunn A, Chenoweth M \& Golden $S$ (1974). Determination of synthesis, recycling and body mass of glucose in rats and rabbits in vivo with ${ }^{3} \mathrm{H}$ and ${ }^{14} \mathrm{C}-\mathrm{la}$ beled glucose. Biochemical J ournal, 142:
170-171.

17. Mondon CE \& Reaven GM (1988). Evidence of abnormalities of insulin metabolism in rats with spontaneous hypertension. Metabolism, 37: 303-305.

18. Swislocky ALM \& Tsuzuky A (1993). Insulin resistance and hypertension: glucose intolerance, hyperinsulinemia and elevated free fatty acids in the lean spontaneously hypertensive rat. American J ournal of Medical Sciences, 306: 282-286.

19. Gaboury $\mathrm{CL}$, Karanja N, Holcomb SR, Torok J \& McCarron DA (1991). Patterns of insulin secretion and responsiveness in Wistar-Kyoto and spontaneously hypertensive rats. American J ournal of Hypertension, 4: 661-666.

20. Hörl WH, Shaefer RM \& Heidland A (1988). Abnormalities of carbohydrate metabolism in spontaneously hypertensive rats. Klinische Wochenschrift, 66: 924-927.

21. J ulius S, Gudbrandsson T, J amerson K, Shahab ST \& Andersson O (1991). The hemodynamic link between insulin resistance and hypertension. J ournal of Hypertension, 9: 983-986.

22. Hall J E, Summers RL, Brands MW, Keen H \& Alonso-Galicia M (1994). Resistance to metabolic actions of insulin and its role in hypertension. American J ournal of Hypertension, 7: 772-778.

23. Mulvany MI (1984). Pathophysiology of vascular smooth muscle in hypertension. J ournal of Hypertension, 2: 413-420. 